\title{
Recomendación para el tratamiento con hipotermia en recién nacidos con encefalopatía hipóxico-isquémica. Resumen ejecutivo
}

Recommendation for therapeutic hypothermia in newborns with hypoxic-ischemic encephalopathy. Executive summary

Grupo de Trabajo Hipotermia Terapéutica,

Comité de Estudios Feto-Neonatales (CEFEN)

http: / / dx.doi.org/10.5546/aap.2017.s38

Texto completo como Suplemento de Archivos Argentinos de Pediatría, en formato electrónico, en su sitio web (véase sección "Suplementos).

\section{INTRODUCCIÓN}

La encefalopatía hipóxicoisquémica (EHI) es una causa importante de daño neurológico agudo en el recién nacido $(\mathrm{RN})$. La hipotermia terapéutica (HT) es, actualmente, el estándar de cuidado para disminuir la morbimortalidad en la población de expuestos. Con el objetivo de unificar criterios de atención de estos pacientes, el Comité de Estudios Feto-neonatales (CEFEN) ha elaborado la siguiente recomendación.

Identificación de los recién nacidos con diagnóstico de encefalopatía hipóxico-isquémica candidatos a recibir tratamiento con hipotermia

- Edad gestacional (EG) $\geq 35$ semanas.

Dra. Silvia Fernández Jonusas: silvia.fernandez@ hospitalitaliano.org.ar

Financiamiento:

Ninguno.

Conflicto de intereses:

Ninguno que declarar.

Recibido: 20-11-2016

Aceptado: 29-11-2016

Cómo citar: Grupo de Trabajo Hipotermia Terapéutica, Comité de Estudios Feto-Neonatales (CEFEN). Recomendación para el tratamiento con hipotermia en recién nacidos con encefalopatía hipóxico-isquémica. Arch Argent Pediatr 2017; 115 Supl 3:s38-s52

Criterios de inclusión

- $\mathrm{pH}$ de cordón o $\mathrm{pH}$ de sangre del bebé en la primera hora de vida $\leq 7$ $\mathrm{y} / \mathrm{o}$ déficit de base $\geq-12$.

- Apgar a los 10 min $\leq 5$.

- Reanimación con ventilación a presión positiva durante más de $10 \mathrm{~min}$.

- Encefalopatía moderada a grave.

Criterios de exclusión

- Pacientes con peso al nacer (PN)
- Trastornos de la coagulación sanguínea que no se corrigen con la administración de plaquetas, plasma y / o crioprecipitados.

- Pacientes cuyo estado general o condición clínica es muy grave y se acuerda con los padres la futilidad del tratamiento.

Manejo en la sala de partos Se recomienda lo siguiente:

- Iniciar la reanimación con aire ambiente, según las guías de reanimación cardiopulmonar (RCP) neonatal de la Sociedad Argentina de Pediatría (SAP), aumentando la concentración de oxígeno al $100 \%$ cuando se realizan compresiones torácicas (RCP avanzado) y disminuyéndola una vez que recupera la frecuencia cardíaca o de acuerdo con la saturometría.

- Utilizar saturometría de pulso. menor de 1800 gramos.
- Colocar un monitor electrocardiográfico.

- La adrenalina debe ser preparada y administrada según se establece en el Manual de Reanimación Cardiopulmonar Neonatal de la Sociedad Argentina de Pediatría. Se deben evitar las expansiones bruscas de la volemia y administración de bicarbonato y/o calcio en forma de bolo.

- Evitar la hipertermia, $\mathrm{T}^{\circ}>37^{\circ} \mathrm{C}$, e hipotermia, temperatura por 
debajo de $33^{\circ} \mathrm{C}$. Cuando se inicia reanimación en pacientes de 35 o más semanas, se sugiere apagar la fuente de calor y colocar el sensor de temperatura central al paciente, una vez establecida la ventilación y una frecuencia cardíaca adecuada, manteniendo un monitoreo de esta con valores de temperatura central en $35{ }^{\circ} \mathrm{C}$ hasta decidir si debe ser incluido en un programa de hipotermia terapéutica. Si el paciente se encuentra en un hospital de baja complejidad, se deberá iniciar el trámite de derivación lo antes posible.

- Realizar un estado ácido-base de cordón umbilical o de sangre arterial lo más cercano posible al nacimiento.

- Evitar la hiperventilación, que podría conducir a hipocapnia, vasoconstricción cerebral y disminución del flujo sanguíneo cerebral.

- Realizar un chequeo de la glucemia para evitar la hipoglucemia posterior a la reanimación.

- Informar a los padres la condición clínica del bebé.

- Informar a la Unidad de Cuidados Intensivos Neonatales (UCIN) la situación clínica del paciente.

\section{Traslado intra- y extrahospitalario}

En el caso de incluirse en protocolo de hipotermia debe realizarse con lo siguiente:

- Incubadora de transporte. Se debe mantener la temperatura corporal entre $34^{\circ} \mathrm{C}$ y $35^{\circ} \mathrm{C}$, y el rango de temperatura rectal entre $33^{\circ} \mathrm{C}$ y $34{ }^{\circ} \mathrm{C}$ con controles cada 15 minutos.

- Saturometría continua y monitoreo electrocardiográfico. Activo control de todos los signos vitales.

- Se debe controlar y registrar la temperatura rectal cada 15 minutos.

- Se debe colocar un acceso venoso con flujo apropiado de glucosa.

- Se debe monitorear la glucemia $(70-120 \mathrm{mg} / \mathrm{dl})$.

\section{MANEJO DEL PACIENTE DURANTE EL TRATAMIENTO CON HIPOTERMIA}

El tratamiento con hipotermia moderada debe llevarse a cabo en unidades de Neonatología de nivel terciario con capacidad de atención multidisciplinaria y con protocolos estandarizados.

\section{Medidas generales}

Se debe monitorear la temperatura central con una sonda rectal introducida de 5 a $6 \mathrm{~cm}$ en el recto o esofágica para evitar episodios de hipertermia o hipotermia excesiva $\left(<33^{\circ} \mathrm{C}\right)$. Se recomienda obtener un valor de temperatura no invasiva. Una temperatura esofágica de $33,5^{\circ} \mathrm{C}$ se corresponde con una temperatura superficial de $31,5^{\circ} \mathrm{C}$ a $32^{\circ} \mathrm{C}$. Todas las decisiones clínicas deben ser tomadas sobre la base de la temperatura central.

La hipotermia debe ser iniciada dentro de las $6 \mathrm{~h}$ del nacimiento a $33,5^{\circ} \mathrm{C}$ si es corporal total $\mathrm{y}$, si es selectiva, el rango de temperatura central es de $34{ }^{\circ} \mathrm{C}-35{ }^{\circ} \mathrm{C}$; la duración debe ser de $72 \mathrm{~h}$.

La Tabla 1 resume los aspectos más importantes para tener en cuenta en el manejo del paciente durante el tratamiento con hipotermia.

\section{Pasos iniciales del tratamiento}

- La preparación del equipo de hipotermia demora, aproximadamente, 30-40 minutos, por lo que es importante considerar este punto.

- Si se dispone de un monitor, se debe iniciar la monitorización continua de la función cerebral mediante electroencefalograma de amplitud integrada (EEGa).

- Se debe dar información a los padres acerca del tratamiento que va a recibir el niño.

Fases

Existen 3 fases en el tratamiento, que tiene como objetivo alcanzar una temperatura determinada, sostenerla en ese nivel durante $72 \mathrm{~h}$ y permitir el recalentamiento en forma lenta.

\section{Fase de enfriamiento}

El objetivo es reducir la temperatura central a $33{ }^{\circ} \mathrm{C}-34{ }^{\circ} \mathrm{C}$ en la hipotermia corporal total y a $34{ }^{\circ} \mathrm{C}-35^{\circ} \mathrm{C}$ en la selectiva de la cabeza en 30 40 minutos. El enfriamiento debe ser más lento en niños con necesidades de oxígeno mayores de $50 \%$ o si aumentan más de $30 \%$ sobre el valor inicial, debido al riesgo de hipertensión pulmonar. La presencia de hipertensión pulmonar no contraindica esta terapia.

\section{Fase de mantenimiento}

En esta etapa, el objetivo es mantener la temperatura deseada durante $72 \mathrm{~h}$ en forma estable. Puede ser necesario prolongar su duración según la respuesta del paciente al recalentamiento (presencia de convulsiones).

En ninguna circunstancia, el tratamiento con hipotermia debe suspenderse por la mejoría 


\section{del estado neurológico del RN (ni clínico ni del registro del EEGa).}

Es importante mantener el confort del paciente. Está indicada la sedación con morfina en dosis menores que las habituales por metabolismo hepático reducido y luego titular la respuesta.

\section{Fase de recalentamiento \\ El objetivo de esta etapa es regresar al niño a la}

temperatura normal en forma lenta y controlada. Se estima un incremento de $0,2^{\circ} \mathrm{C}-0,5^{\circ} \mathrm{C}$ por hora.

\section{Riesgos durante esta fase \\ Hiperkalemia, convulsiones e hipotensión arterial. \\ Luego de alcanzar una temperatura central de $36,5^{\circ} \mathrm{C}-37^{\circ} \mathrm{C}$, puede retirarse la sonda rectal o esofágica y continuar el control de la temperatura con mediciones periféricas.}

TABLA 1. Aspectos más importantes para tener en cuenta en el manejo del paciente durante el tratamiento con hipotermia

\begin{tabular}{|c|c|}
\hline $\begin{array}{l}\text { Respiratorio Se debe } \\
\text { intubar y ventilar } \\
\text { en los siguientes casos: }\end{array}$ & $\begin{array}{l}\text { - Respiraciones espontáneas ineficaces. } \\
\text { - Desaturación a pesar de la administración de oxígeno }\left(\mathrm{O}_{2}\right) \text { a flujo libre. } \\
\text { - Insuficiencia respiratoria en los gases sanguíneos. } \\
\text { - Crisis convulsivas tempranas que interfieran con la respiración. } \\
\text { La administración de } \mathrm{O}_{2} \text { mediante una cánula nasal probablemente sea una mejor estrategia que el uso } \\
\text { de halo cefálico con el objetivo de evitar la hipertermia. } \\
\text { Se debe monitorear la saturación de } \mathrm{O}_{2} \text { continua, con un objetivo de saturación preductal de } 90 \% \text { a } 95 \% \text {. } \\
\text { Se deben realizar ajustes del respirador con los objetivos trazados de límites de presión parcial de } \\
\text { dióxido de carbono }\left(\mathrm{pCO}_{2}\right) \text { y presión parcial de oxígeno }\left(\mathrm{PO}_{2}\right) \text {. } \\
\text { Se debe realizar estado ácido-base (EAB) de acuerdo con las necesidades del paciente. }\end{array}$ \\
\hline Cardiovascular & $\begin{array}{l}\text { Se debe realizar la monitorización cardiorrespiratoria continua con monitor multiparamétrico } \\
\text { (frecuencia cardíaca, frecuencia respiratoria, presión arterial). } \\
\text { Se debe realizar una ecocardiografía. } \\
\text { La hipotensión es una consecuencia común de la isquemia miocárdica. } \\
\text { Solo si se sospecha hipovolemia, se deben dar } 10-20 \mathrm{ml} / \mathrm{kg} \text { de solución fisiológica. } \\
\text { Se debe considerar administrar inotrópicos. } \\
\text { Se debe recordar que la hipoxia produce alteración de las enzimas miocárdicas, por lo tanto, es } \\
\text { aconsejable solicitar su dosaje al ingresar y posteriormente. } \\
\text { Se deben monitorear los valores de ácido láctico. }\end{array}$ \\
\hline Metabólico & $\begin{array}{l}\text { Se deben realizar controles de glucemia y EAB. } \\
\text { Se debe solicitar un hepatograma. } \\
\text { Se debe asegurar el aporte de un flujo de glucosa suficiente para prevenir hipoglucemia y monitorear } \\
\text { los niveles de glucosa para evitar hiperglucemia. } \\
\text { Se deben evitar correcciones con bicarbonato teniendo en cuenta las causas de acidosis metabólicas } \\
\text { para tratarlas. }\end{array}$ \\
\hline
\end{tabular}

Líquidos y electrolitos Se debe colocar una sonda nasogástrica (SNG) abierta.

Se deben restringir los fluidos a 40-50 $\mathrm{ml} / \mathrm{kg} /$ día. La restricción de líquidos es esencial debido al riesgo de secreción inapropiada de hormona antidiurética (SIHAD) e insuficiencia renal.

Se debe evaluar el ritmo diurético.

Se debe realizar el control de electrolitos, calcio, magnesio, urea y creatinina.

Nutricional Se debe iniciar nutrición parenteral total (NPT) desde el primer día de vida y considerar los beneficios de administrar calostro.

Infectológico Si existe la posibilidad de sepsis, se deben tomar cultivos de sangre y comenzar un tratamiento antibiótico con ampicilina y gentamicina. Se debe realizar la curva de reacción en cadena de la polimerasa (polymerase chain reaction; PCR, por sus siglas en inglés) cuantitativa y, si los cultivos son negativos, suspender los antibióticos precozmente.

Neurológico

Si se dispone del equipo, se debe realizar un electroencefalograma de amplitud integrada (EEGa). Se debe realizar una ecografía cerebral para descartar malformaciones del sistema nervioso central (SNC) o hemorragias. 
Monitoreo por electroencefalograma de amplitud integrada

De contar con este equipo, su uso aportará datos de convulsiones, pronóstico y trazado fácilmente interpretable.

Se amplían los conceptos referentes al monitor en la versión on-line.

\section{Eventos adversos}

Plaquetopenia, bradicardia, necrosis grasa subcutánea.

Estudio del sistema nervioso central con imágenes

La resonancia magnética (RMN) cerebral es el estudio de elección para evaluar la lesión hipóxicoisquémica del RN y se recomienda su realización luego del $4^{\text {to }} \mathrm{o} 5^{\text {to }}$ día de vida y antes del día 10 .
La tomografía computarizada ofrece menor definición y se restringe ante la sospecha de patología neuroquirúrgica.

La ecografía cerebral es inocua y altamente accesible, útil para tener una primera aproximación en caso de niños inestables.

Potenciales auditivos evocados automatizados: se debería realizar, al menos, un estudio antes del egreso del paciente de la Unidad.

\section{Seguimiento del paciente}

El alta del paciente con diagnóstico de EHI obliga a su inclusión en un programa de seguimiento multidisciplinario (pediatra, neurólogo, fisiatras de rehabilitación, psicólogos y servicio social) para su atención y la de su familia.

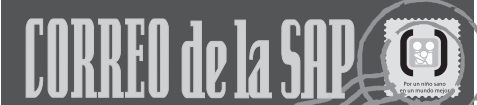

Los siguientes resúmenes y comentarios de trabajos seleccionados se encuentran disponibles en la versión electrónica de este número.

PEDIATRICS 2017 Jan;139(1)

Cuidado seco vs. antisépticos para el cuidado del cordón umbilical: estudio aleatorizado por clusters (Gras-Le Guen C, et l. Dry care versus antiseptics for umbilical cord care: a cluster randomized trial) Comentario: Dr. Ernesto Alda. Jefe Servicio de Neonatología. Hospital Privado del Sur. Bahia Blanca.

J CYST FIBROS 2016;15(6):791-793

Fibrosis quística en Latinoamérica - Mejorar el conocimiento (Silva Filho LV, et al. Cystic fibrosis in Latin America - Improving the awareness)

Comentario: Dr. Fernando Rentería. Servicio de Neumonología. Hospital Sor María Ludovica, La Plata, Buenos Aires.

ARCH DIS CHILD 2017 Jan 19

YouTube: ¿Los vídeos de sus hijos enfermos son una fuente útil de información médica para otros padres? (Katie Knight, et al. YouTube: are parent-uploaded videos of theirunwell children a useful source of medical information for other parents?)

Comentario: Dra. Paula Otero. Hospital Italiano de Buenos Aires.

N ENGL J MED 2017;376:11-20

Epidemiología de la Injuria renal aguda en niños y adultos jóvenes críticamente enfermos (Ahmad Kaddourah, et al. Epidemiology of acute kidney injury in critically ill children and young adults)

Comentario: Dr. Daniel Buamscha. Área de Terapia Intensiva. Hospital de Pediatría Juan P. Garrahan Dra. Alicia Fayad. Servicio de Nefrología. Hospital de Niños Ricardo Gutiérrez.

PEDIATRICS 2016;138(2):e20154381

Validación del abordaje "paso a paso" en el manejo de lactantes pequeños con fiebre (Borja Gomez, et al. Validation of the "step-by-step" approach in the management of young febrile infants)

Comentario: Dr. José M. Ceriani Cernadas. Hospital Italiano de Buenos Aires.

ARCH DIS CHILD 2017;102(3):224-231

Vacunación BCG al nacimiento y hospitalización en la primera infancia: un estudio clínico aleatorizado multicéntrico (Stensballe LG, et al. BCG vaccination at birth and early childhood hospitalisation: a randomized clinical multicentre trial)

Comentario: Dr. Matías Oleastro. Servicio de Inmunología y Reumatología. Hospital Nacional de Pediatría "Prof. Dr. Juan P. Garrahan". 